\title{
The safety of outpatient total shoulder arthroplasty: a systematic review and meta-analysis
}

\author{
Abdulaziz F. Ahmed ${ }^{1}$ (D) - Ashraf Hantouly ${ }^{1} \cdot$ Ammar Toubasi $^{1} \cdot$ Osama Alzobi ${ }^{1} \cdot$ Shady Mahmoud $^{2}$. \\ Saeed Qaimkhani ${ }^{1} \cdot$ Ghalib O. Ahmed $^{1} \cdot$ Mohammed Al Ateeq Al Dosari $^{1}$
}

Received: 23 July 2020 / Accepted: 7 January 2021 / Published online: 23 January 2021

(C) The Author(s) 2021

\begin{abstract}
Purpose To meet the increasing demands of total shoulder arthroplasty (TSA) while reducing its financial burden, there has been a shift toward outpatient surgery. This systematic review and meta-analysis aimed to evaluate the safety of outpatient TSA.

Methods The primary objective was to compare re-admission rates and postoperative complications in outpatient versus inpatient TSA. The secondary objectives were functional outcomes and costs. PubMed, Google Scholar, and Web of Science were searched until March 28, 2020. The inclusion criteria were studies reporting at least complications or readmission rates within a period of 30 days or more.

Results Ten level III retrospective studies were included with 7637 (3.8\%) and 192,025 (96.2\%) patients underwent outpatient and inpatient TSA, respectively. Outpatient TSA had relatively younger and healthier patients. There were no differences between outpatient and inpatient arthroplasty for 30- and 90-day readmissions. Furthermore, unadjusted comparisons demonstrated significantly less total and major surgical complications, less total, major, and minor medical complications in favour of outpatient TSA. However, subgroup analyses demonstrated that there were no significant differences in all complication if the studies had matched controls and regardless of data source (database or nondatabase studies). The revision rates were similar between both groups at a 12-24 months follow-up. Two studies reported a significant reduction in costs in favour of outpatient TSA.

Conclusion This study highlights that outpatient TSA could be a safe and effective alternative to inpatient TSA in appropriately selected patients. It was evident that outpatient TSA does not lead to increased readmissions, complications, or revision rates. A potential additional benefit of outpatient TSA was cost reduction.
\end{abstract}

Keywords Outpatient $\cdot$ Ambulatory $\cdot$ Total shoulder $\cdot$ Arthroplasty $\cdot$ Meta-analysis $\cdot$ Systematic review

\section{Introduction}

Total shoulder arthroplasty (TSA) is a successful procedure to treat end-stage glenohumeral osteoarthritis, rotator cuff arthropathy, and proximal humerus fractures. The frequency of TSA is on the rise in the USA with a five-fold increase in

Level of Evidence: III, Therapeutic

Abdulaziz F. Ahmed

afahmed@alumni.harvard.edu

1 Section of Orthopedics, Department of Surgery, Orthopaedic Surgery Resident, Hamad General Hospital, PO Box 3050, Doha, Qatar

2 Department of Orthopaedic Surgery, Albert Einstein College of Medicine, Bronx, NY, USA the past decade $[1,2]$ and a reported annual incidence of 9.4 $12.3 \%[3,4]$. Improvement in implant design, surgical technique, and peri-operative management resulted in a substantial reduction in length of stay and post-operative complications $[5,6]$.

Health care systems are shifting toward maximizing the value of care through reducing costs while providing high-quality patient care. In an economic analysis on TSA, $24 \%$ of total costs per patient were attributed to inpatient costs, whereas, $6 \%$ was due to 90 -day followup costs [7]. Thus, there has been an increased interest in transitioning toward outpatient TSA, with a reported $107 \%$ increase over the past five years [8]. This transition has been motivated by the well-established safety and financial effectiveness of outpatient total hip and knee arthroplasty [9-13]. 
To achieve a successful outpatient pathway, careful patient risk stratification is paramount to identify who can undergo outpatient arthroplasty safely without increasing readmissions and complications [14]. This requires tremendous cooperation across several stakeholders such as surgeons, anesthesiologists, nurses, administration, insurance agencies, and rehabilitation services [15]. Several studies have shown that adjusting patient expectations, proper patient education, inquiry about living status such as the availability of assistance at home, and proximity to the surgical centre are crucial when considering outpatient pathways [16-19]. Furthermore, pain management should be carefully planned with the anaesthetists which can include preemptive analgesia, brachial plexus catheters, interscalene blocks, peri-articular injections, and post-operative multimodal pain management $[16,20]$.

The primary objective of this systematic review was to determine the safety of outpatient TSA by comparing the outpatient and inpatient pathways in terms of readmission rates and post-operative complications. The secondary objective was to compare the functional outcomes and costs of outpatient with inpatient TSA. We hypothesize that outpatient TSA would have similar readmission rates, complications, revisions, functional outcomes, and reduced costs compared with inpatient TSA.

\section{Methods}

This systematic review and meta-analysis was conducted with adherence to the guidelines of the Preferred Reporting Items for Systematic Reviews and Meta-Analyses (PRISMA) [21].

\section{Eligibility criteria}

Studies comparing outpatient with primary inpatient TSA were sought. Outpatient TSA was defined as having a length of stay less than 24 hours following TSA, whereas the inpatient counterpart was defined as having a length of stay for more than 24 hours. The inclusion criteria were studies reporting at least complications or readmission rates within a period of 30 days or more. The exclusion criteria entailed studies that were noncomparative; studies published in languages other than English; studies that included primary TSA for trauma, hemiarthroplasty, or revision TSA.

\section{Search strategy}

PubMed, Google Scholar, and Web of Science were searched until March 28, 2020. The keywords used in each database were "Shoulder" AND "Arthroplasty" AND ("Outpatient" OR "Ambulatory") AND "Inpatient". Studies were screened by titles and abstracts. A full-text review was performed if a study matched the eligibility criteria. Furthermore, the references of each eligible article were manually sought to ensure no eligible studies were missing. The search strategy was performed by two authors independently.

\section{Data items}

Data collection forms were used independently by two authors. The data items that were collected included the first authors' surnames, study year and location, age, sex, number of patients, the treatments performed, follow-up time points, readmission rates, post-operative complications, functional outcomes, and cost.

The complications were divided into medical and surgical complications, and each was further subdivided into major and minor complications [22, 23]. Medical complications were defined as a systemic adverse event, and surgical complications were defined as adverse events that occur locally at the surgical site. Minor complications are adverse events that do not compromise the final treatment outcome and are treated with brief pharmacotherapy or minor surgical intervention. Major complications are adverse events that significantly alter the normal postoperative course and may require further surgical procedures or prolonged pharmacotherapy.

\section{Qualitative assessment}

The qualitative assessment (i.e., risk of bias assessment) was performed with the Risk of Bias in Non-randomized Studies of Interventions (ROBINS-I) tool [24]. The tool assesses bias at three stages: pre-intervention, at intervention, and postintervention. The pre-intervention stage has two domains of bias which includes bias due to confounding and bias due to selection of participants into the study. The at intervention stage is concerned with bias in classification of interventions. The post-intervention stage contains four types of bias which include bias due to deviation from intended intervention, bias due to missing data, bias in measurement of outcomes, and bias in selection of reported results. Therefore, seven domains of bias were assessed per study. Each study was assessed by two authors independently by using the ROBINS-I tool detailed guide. The level of bias for each domain was evaluated through signaling questions, which in turn provides a final judgement for the risk of bias within each domain. The risk of bias within each domain was then classified as low risk, moderate risk, serious risk, or critical risk as per the ROBINSI guide. An overall judgement for the level of bias per study was then determined after performing the risk of bias judgement to all seven domains of bias. A studied is determined to have low risk of bias is it comparable to a well-performed randomized trial, moderate risk of bias if a study is a sound non-randomized study but not comparable to a randomized study, serious risk of bias if a study has some important 
Fig. 1 The search strategy flowchart

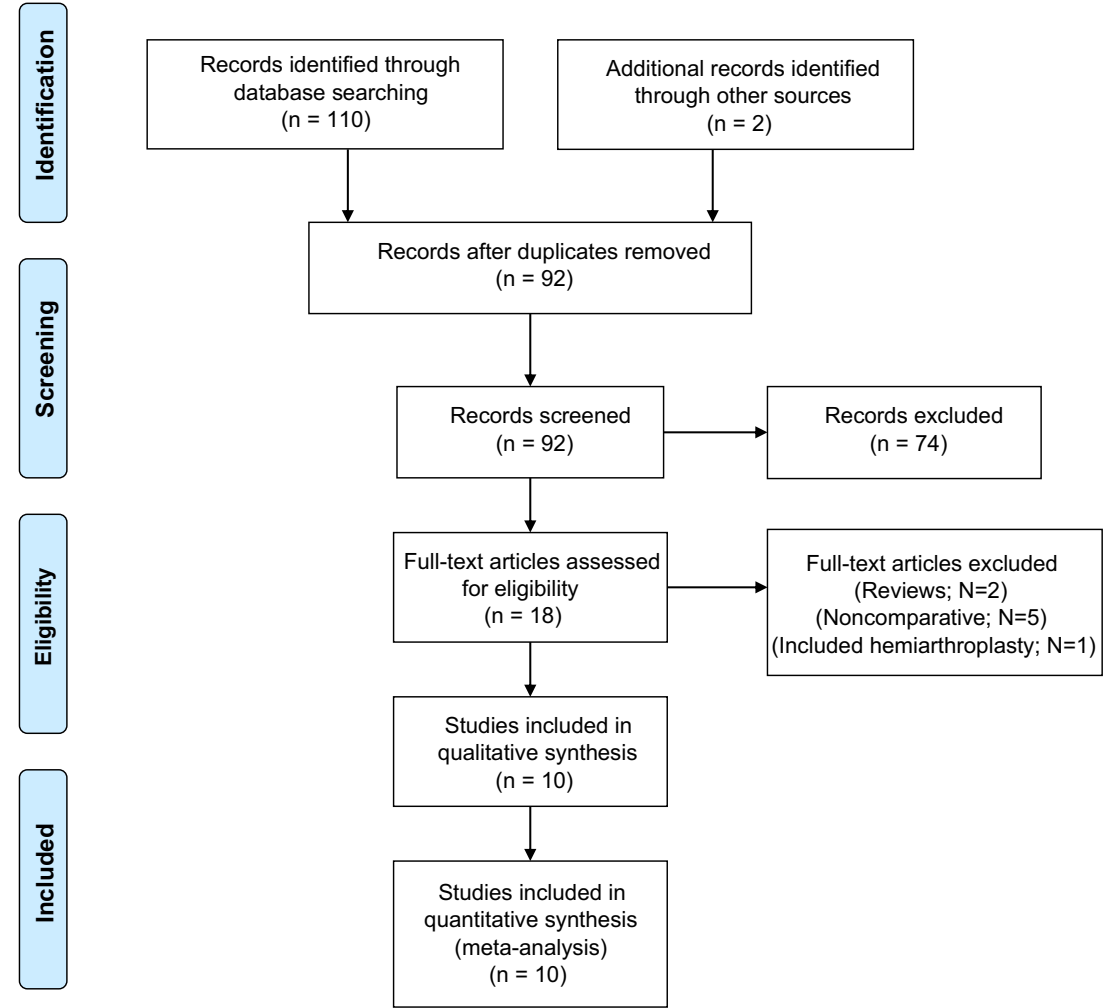

problems, and critical risk of bias if a study is too problematic to provide any useful evidence.

\section{Quantitative analysis}

The quantitative synthesis (i.e., statistical combination of data) was performed with the use of Stata/IC (StataCorp. 2019. Stata Statistical Software: Release 16. College Station, TX: StataCorp LLC.). Patients' characteristics were pooled to provide an estimate using percentages for dichotomous variables or analytical weighted means for continuous variables. Percentages were compared with the test of proportions and a $P$ value $<0.05$ was considered significant. The outcomes were estimated with the use of $95 \%$ confidence interval (CI). The odds ratio (OR) was utilized for dichotomous outcomes. The meta-analytic models were based on random effects with the use of the DerSimonian-Laird method as a heterogeneity variance estimator.

\section{Additional quantitative analysis}

Subgroup analyses were constructed for outcomes that had significant heterogeneity and to further ascertain the outcomes of outpatient TSA. The first subgroup analysis was based on whether a controlled study had matched controls. The second subgroup was based on the data source utilized such as database or nondatabase. The heterogeneity was quantified with the $I^{2}$ statistic which represents the percentage of total variation across study due to heterogeneity rather than due to chance. An $I^{2}$ statistic between 0 and $40 \%$ indicated nonimportant heterogeneity, 30-60\% indicated moderate heterogeneity, $50-90 \%$ indicated substantial heterogeneity, and considerable heterogeneity was assumed when an $I^{2}$ statistic ranged between 75 and $100 \%$.

\section{Results}

\section{Study selection}

The literature search identified 110 articles of which 18 duplicate articles were excluded, thus leaving 92 articles for screening by titles and abstracts. A total of 74 articles did not match the inclusion criteria and were excluded, resulting in 18 articles eligible for full-text reviews. Of the 18 articles, eight articles were excluded which resulted in ten eligible articles that were included in the qualitative assessment and qualitative synthesis. The PRISMA flowchart is displayed in Fig. 1 and provides details on excluded articles.

\section{Study characteristics}

All studies were retrospective comparative studies with a level III evidence. The data sources were based on registries or databases in six studies and nondatabased in the other four 
Table 1 Characteristics of included studies

\begin{tabular}{|c|c|c|c|c|c|c|c|}
\hline \multirow{2}{*}{$\begin{array}{l}\text { Study } \\
\text { Ode et al. } 2020 \\
{[25]}\end{array}$} & \multirow{2}{*}{$\begin{array}{l}\text { Study type, LoE } \\
\text { Retrospective cohort, III }\end{array}$} & \multirow{2}{*}{$\begin{array}{l}\text { Data source } \\
\text { State Inpatient and Ambulatory } \\
\text { Surgery Databases }\end{array}$} & \multirow{2}{*}{$\begin{array}{l}\text { Procedure } \\
\begin{array}{l}\text { aTSA + } \\
\text { rTSA }\end{array}\end{array}$} & \multicolumn{2}{|c|}{$\begin{array}{l}\text { Outpatient/ } \\
\text { inpatient }(\mathrm{N})\end{array}$} & \multirow{2}{*}{$\begin{array}{l}\text { Outcomes } \\
\text { Readmission costs }\end{array}$} & \multirow{2}{*}{$\begin{array}{l}\text { Follow-up } \\
90 \text { days }\end{array}$} \\
\hline & & & & 974 & 37,881 & & \\
\hline 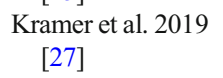 & Retrospective cohort, III & $\begin{array}{l}\text { Kaiser Permanente's Shoulder } \\
\text { Arthroplasty Registry }\end{array}$ & $\begin{array}{r}\text { aTSA + } \\
\text { rTSA }\end{array}$ & 405 & 6098 & $\begin{array}{l}\text { Readmission } \\
\text { complications }\end{array}$ & $\begin{array}{l}90 \text { days for readmissions } \\
1 \text { year for mortality }\end{array}$ \\
\hline $\begin{array}{l}\text { Erickson et al. } \\
2019[18]\end{array}$ & Retrospective cohort, III & Nondatabase & rTSA & 241 & 373 & $\begin{array}{l}\text { Complications } \\
\text { Function }\end{array}$ & 2 years \\
\hline $\begin{array}{l}\text { Nelson et al. } 2019 \\
\quad[19]\end{array}$ & Retrospective cohort, III & Nondatabase & aTSA & 35 & 46 & $\begin{array}{l}\text { Readmissions } \\
\text { complications }\end{array}$ & 90 days \\
\hline $\begin{array}{l}\text { Arshi et al. } 2018 \\
\text { [29] }\end{array}$ & Retrospective cohort, III & Humana database, Pearl-Diver & $\begin{array}{r}\text { aTSA + } \\
\text { rTSA }\end{array}$ & 1555 & 15,987 & Complications & $\begin{array}{l}14 \text { days for pneumonia, } \\
\text { AKI, RF } \\
30 \text { days for MI and CVA } \\
60 \text { days for VTE } \\
1 \text { year for surgical } \\
\text { complications }\end{array}$ \\
\hline $\begin{array}{l}\text { Bean et al. } 2018 \\
\quad[16]\end{array}$ & Retrospective cohort, III & Nondatabase & $\begin{array}{r}\text { aTSA + } \\
\text { rTSA }\end{array}$ & 21 & 40 & $\begin{array}{l}\text { Readmissions } \\
\text { complications }\end{array}$ & 90 days \\
\hline $\begin{array}{l}\text { Cancienne et al. } \\
2017[8]\end{array}$ & $\begin{array}{l}\text { Retrospective cohort, III } \\
\quad \text { (matched controls) }\end{array}$ & Humana database, Pearl-Diver & aTSA & 706 & 4459 & $\begin{array}{l}\text { Readmissions } \\
\text { complications } \\
\text { Costs }\end{array}$ & $\begin{array}{l}30,90 \text { days for } \\
\text { readmissions } \\
90 \text { days for medical } \\
\text { complications } \\
1 \text { year for surgical } \\
\text { complications }\end{array}$ \\
\hline $\begin{array}{l}\text { Brolin et al. } 2017 \\
{[17]}\end{array}$ & $\begin{array}{l}\text { Retrospective cohort, III } \\
\text { (matched controls) }\end{array}$ & Nondatabase & aTSA & 30 & 30 & $\begin{array}{l}\text { Re-admissions } \\
\text { Complications }\end{array}$ & 90 days \\
\hline $\begin{array}{l}\text { Basques et al. } \\
\quad 2017[28]\end{array}$ & Retrospective cohort, III & $\begin{array}{l}\text { The US Medicare standard } \\
\text { analytical file }\end{array}$ & $\begin{array}{r}\text { aTSA + } \\
\text { rTSA }\end{array}$ & 3493 & 119,854 & $\begin{array}{l}\text { Readmissions } \\
\text { complications }\end{array}$ & 30 and 90 days \\
\hline $\begin{array}{l}\text { Leroux et al. } 2016 \\
\text { [26] }\end{array}$ & Retrospective cohort, III & ACS NSQIP database & $\begin{array}{r}\text { aTSA + } \\
\text { rTSA }\end{array}$ & 173 & 7024 & $\begin{array}{l}\text { Readmissions } \\
\text { complications }\end{array}$ & 30 days \\
\hline
\end{tabular}

$L o E$ level of evidence; $a T S A$ anatomic total shoulder arthroplasty; $r T S A$ reverse total shoulder arthroplasty; $A K I$ acute kidney injury; $R F$ respiratory failure; MI myocardial infarction; CVA cerebrovascular accident; VTE venous thromboembolism; ACS American College of Surgeons; NSQIP National Surgical Quality Improvement Program

studies. Three studies focused on anatomic TSA, one study on reverse TSA, and six studies included both anatomic and reverse TSA.

The total number of the population included was 199,662 cases of TSAs, with 7637 (3.8\%) patients who underwent outpatient TSAs, and 192,025 (96.2\%) patients underwent inpatient TSAs. Eight $[8,16,17,19,25-28]$ out of the ten studies reported readmission rates and nine studies reported postoperative complications. Two studies $[8,25]$ reported costs in the form of total charges or cost per patient, and one study [18] reported shoulder functional scores. The summary of the included studies is provided in Table 1.

\section{Patients characteristics}

Patients' demographics are crucial when comparing outpatient with inpatient pathways. The two studies by Cancienne et al. [8] and Brolin et al. [17] had matched controls; however, the remaining eight studies were unmatched cohort studies. The summary of the patients' baseline characteristics of all studies is available as Supplementary Material I.

In the two matched cohorts, the age and patients' comorbidities were similar between outpatient and inpatient group; however, Brolin et al. [17] had more males in the outpatient group.

For the eight unmatched studies, patients who underwent outpatient TSA were significantly younger in five studies. In addition, the outpatient pathway had significantly more males (50.5\% vs 39\%), lower proportions of American Society of Anaesthesiologist (ASA) class III patients (35.2\% vs $48.4 \%$ ), less diabetes ( $14.2 \%$ vs $19.3 \%)$, less combined cardiopulmonary comorbidities ( $11.5 \%$ vs $20.2 \%)$, less isolated cardiovascular comorbidities (19.4\% vs $24.4 \%$ ), and less hypertension (51.4\% vs $67.6 \%)$. However, outpatient TSA had a higher prevalence of obesity ( $16.8 \%$ vs $15.7 \%)$ and smokers $(8.1 \%$ vs $5 \%$ ). There was no difference in isolated pulmonary comorbidities (18.9\% vs $18.8 \%$ ). These results suggest that current patient selection for outpatient TSA results in a relatively healthier patient population. The pooled estimates with comparisons for the unmatched studies are summarized in Table 2 .

\section{Qualitative assessment}

The methodological quality of most included studies was poor which is relatable to the data sources utilized in these studies and the retrospective design (Supplementary Material II). 
Table 2 Pooled estimated for patients' characteristics in unmatched studies

\begin{tabular}{|c|c|c|c|c|c|}
\hline \multirow[t]{2}{*}{ Characteristic } & \multirow[t]{2}{*}{ No. of studies } & \multirow{2}{*}{$\begin{array}{l}\text { Total sample size } \\
\text { Outpatient/inpatient }\end{array}$} & \multicolumn{3}{|c|}{ Pooled estimate } \\
\hline & & & Outpatient & Inpatient & $P$ value \\
\hline Male sex $(\%)$ & $8^{1-3 ; 14 ; 20 ; 21 ; 26 ; 27}$ & $6901 / 187,536$ & $50.5 \%$ & $39 \%$ & $<0.001 *$ \\
\hline ASA class $\geq$ III $(\%)$ & $3^{14 ; 20 ; 21}$ & $599 / 13,162$ & $35.2 \%$ & $48.4 \%$ & $<0.001 *$ \\
\hline Diabetes & $8^{1-3 ; 14 ; 20 ; 21 ; 26 ; 27}$ & $6901 / 187,536$ & $14.2 \%$ & $19.3 \%$ & $<0.001 *$ \\
\hline Cardiopulmonary comorbidity & $2^{3 ; 27}$ & $999 / 38,154$ & $11.5 \%$ & $20.2 \%$ & $<0.001 *$ \\
\hline Cardiovascular comorbidity & $3^{2 ; 20 ; 26}$ & $3933 / 125,998$ & $19.4 \%$ & $24.4 \%$ & $<0.001^{*}$ \\
\hline Pulmonary comorbidity & $4^{2 ; 20 ; 21 ; 26}$ & $4106 / 133,022$ & $18.9 \%$ & $18.8 \%$ & 0.87 \\
\hline Hypertension & $2^{21 ; 26}$ & $208 / 7070$ & $51.4 \%$ & $67.6 \%$ & $<0.001 *$ \\
\hline Mean $\mathrm{BMI} \dagger$ & $4^{3 ; 14 ; 26}$ & $297 / 459$ & 29.9 & 31.42 & - \\
\hline Obesity & $4^{2 ; 20 ; 21 ; 27}$ & $5049 / 171,090$ & $16.8 \%$ & $15.7 \%$ & $0.034 *$ \\
\hline Smoker & $6^{2 ; 3 ; 14 ; 20 ; 21 ; 26}$ & $4368 / 133,435$ & $8.1 \%$ & $5 \%$ & $<0.001 *$ \\
\hline
\end{tabular}

ASA American Society of Anaesthesiologists; BMI body mass index. (*) Asterisk denotes a statistically significant comparison

There was significant confounding in six out of ten studies and selection bias in seven out of ten studies which can be attributed to the difference in patients' characteristics. Three studies had a moderate risk for missing data, and two studies had a moderate bias of selection of reported results. In terms of measurement of outcomes, two studies had a serious risk for bias while the rest of the studies had a moderate risk of bias. All studies had a low risk of bias for the classification of interventions and deviations from intended interventions.

\section{Readmissions}

Readmission rates were reported in eight out of ten studies. Only the database study by Basques et al. [28] reported significantly fewer readmissions within 90 days in favour of outpatient TSA. On the other hand, the rest of the matched and unmatched studies found no difference between both groups.

The readmission rate within 30 days in three studies resulted in an OR of 0.9 [95\% CI 0.63, 1.3] $\left(I^{2}=33.8 \%\right.$ ) (Fig. 2), whereas the readmissions within 90 days in seven studies resulted in an OR of 0.91 [95\% CI $0.7,1.2]\left(I^{2}=56.3 \%\right)$ (Fig. 3). Furthermore, subgroup analyses adjusting for matched studies and data sources had no significant differences for the 90-day readmissions.

\section{Complications and revisions}

Among database studies, Leroux et al. [26] reported that the crude overall complications were less in outpatient TSA ( $2.3 \%$ vs. $7.9 \%)$; however, the difference was not statistically significant following a multivariate analysis $(P=0.77)$. Similarly, Kramer et al. [27] failed to observe any difference in terms of one year mortality, 90-day deep infections and venous thromboembolism VTE. However, Basques et al. [28] reported that outpatient TSA was associated with lower thromboembolic events and surgical site infections. Additionally, Cancienne et al. [8] found that outpatient TSA had significantly less urinary tract infections $(P=0.003)$ and less blood transfusions $(P=0.028)$ [8]. On the other hand, Arshi et al. [29] found that outpatient TSA was associated with higher rates of surgical site infections.

In non-database studies, only the study by Erickson et al. [18] found that outpatient TSA had lower overall complications ( $7 \%$ vs $12.7 \% ; P=0.23$ ). All other four nondatabase
Fig. 2 Comparison of 30-day readmissions between outpatient and inpatient total shoulder arthroplasty (TSA). CI: confidence interval

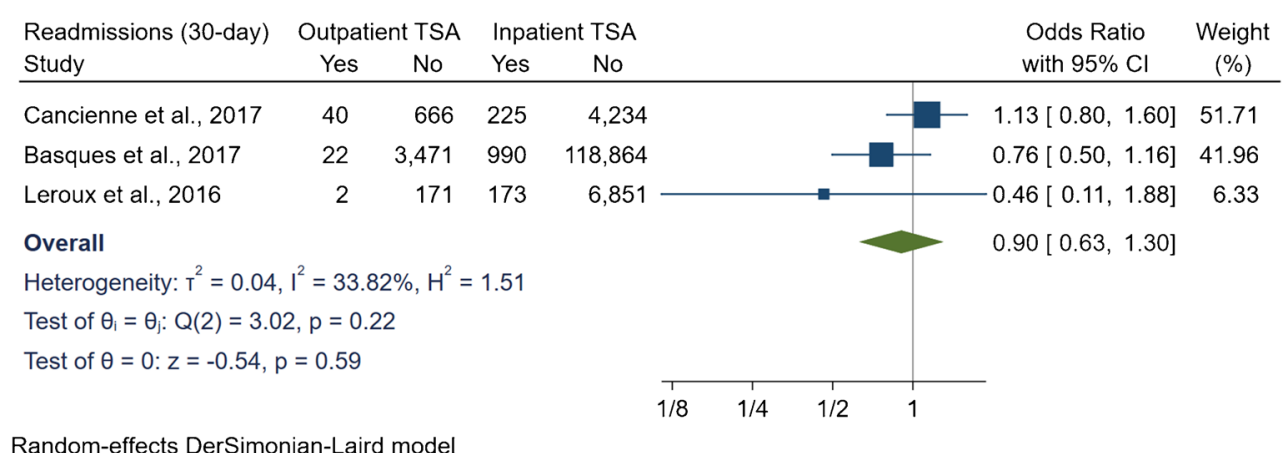




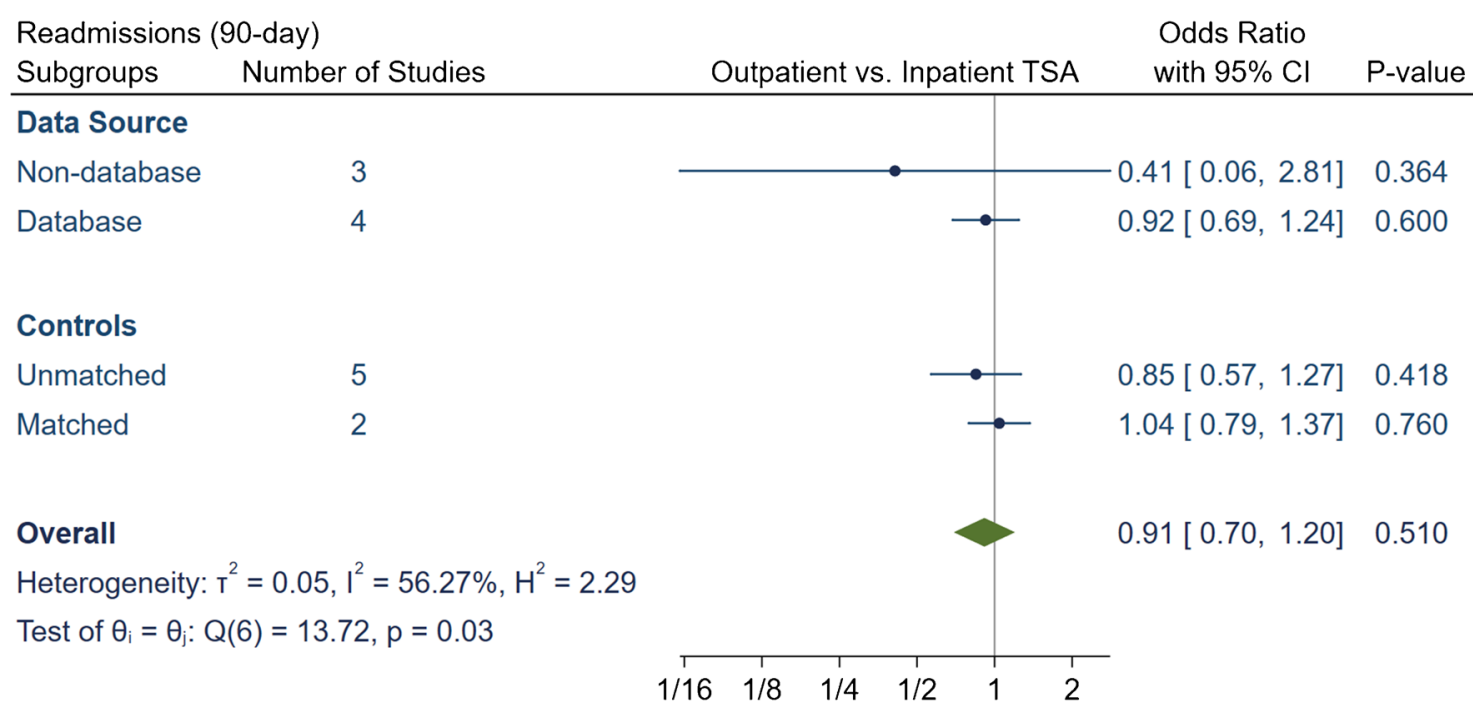

Random-effects DerSimonian-Laird model

Fig. 3 Comparison of overall 90-day readmissions between outpatient and inpatient total shoulder arthroplasty (TSA) with subgroup analyses for data source and controls. CI: confidence interval

studies failed to demonstrate any difference in medical and surgical complications.

The total number of surgical complications in the outpatient group was 174 (2.6\%), of which 114 (1.7\%) were major and $60(0.9 \%)$ were minor surgical complications (Table 3$)$. The inpatient group had a total of $7872(5.1 \%)$ surgical complications, of which 2044 (1.3\%) complications were major and $5828(3.8 \%)$ were minor. Our meta-analytic comparison on nine studies demonstrated an overall OR of 0.58 [95\% CI $0.35,0.97]\left(I^{2}=78.7 \%\right)$ for total surgical complications (Fig. 4), an OR of 0.67 [95\% CI 0.46, 0.97] $\left(I^{2}=47.03 \%\right)$ for major surgical complications (Fig. 5) and an OR of 1.1 [95\% CI $0.37,3.27]\left(I^{2}=51.5 \%\right)$ for minor surgical complications (Fig. 6). Subgroup analyses demonstrated that the overall reduction in total and major surgical complications in outpatient TSA was attributed to unmatched studies. No significant difference in total or major surgical complications was found if studies had matched controls, or if studies were stratified by data source. Additionally, no statistically significant differences were found in minor surgical complications between outpatient or inpatient TSA despite subgroup analyses were employed.

The total number of medical complications in the outpatient group was $252(3.8 \%)$, of which $179(2.7 \%)$ were major and $73(1.1 \%)$ were minor medical complications (Table 4). The inpatient group had a total of 10,158 (6.6\%) medical complications, of which 4041 (2.6\%) complications were major and 6117 (4\%) were minor. The meta-analytic comparison in nine studies displayed outpatient TSA had an OR of 0.55 [95\% CI $0.35,0.86$ ] $\left(I^{2}=82.1 \%\right)$ for total medical complications (Fig. 7), an OR of 0.62 [95\% CI $0.41,0.94$ ] $\left(I^{2}=66.9 \%\right)$ for major medical complications (Fig. 8) and an OR of 0.49 [95\%
CI $0.28,0.85]\left(I^{2}=26.8 \%\right)$ for minor medical complications (Fig. 9). Subgroup analyses demonstrated that the significantly lower total, major and minor medical complication rate in outpatient arthroplasty was only evident if the studies were unmatched. Otherwise no significant differences were detected between outpatient or inpatient TSA in matched studies or if studies were grouped based on data source.

The revision rates were reported in three studies, with a revision incidence of $1.9 \%(N=50)$ in the outpatient group and $1.6 \%(N=346)$ in the inpatient group. At 12 month follow-up, Cancienne et al. [8] and Arshi et al. [29] found no statistically significant difference in TSA revision at 12 months. Similarly, Erickson et al. [18] reported no difference in revision between both groups at 24 months. In addition, our meta-analytic comparison resulted in an OR of 1.02 [95\% CI $0.75,1.39]\left(I^{2}=0 \%\right)$ when pooling the revision rates at a follow-up period ranging from 12 to 24 months (Fig. 10). The main indications for revision reported were for periprosthetic infection, loosening, instability, periprosthetic fractures, stiffness, distal clavicle excision, and conversion to hemiarthroplasty.

\section{Shoulder functional outcomes}

Functional outcomes were reported in the study by Erickson et al. [18] with the use of the American Shoulder and Elbow Society score and the Single Assessment Numeric Evaluation. At one and two years post-operatively, the outpatient and inpatient groups had significant improvements on both scores; however, no statistically significant difference was reported between the two groups. 


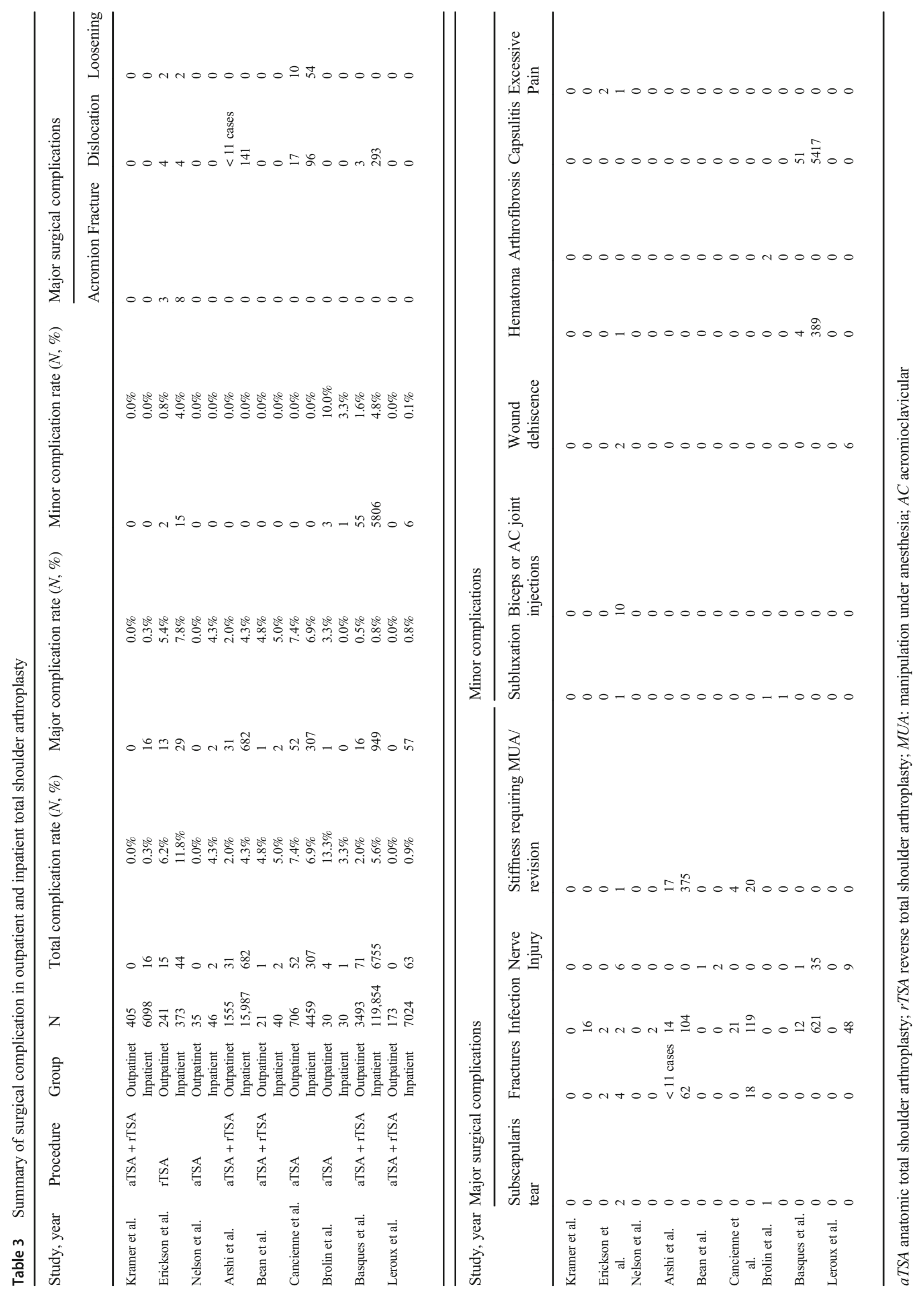




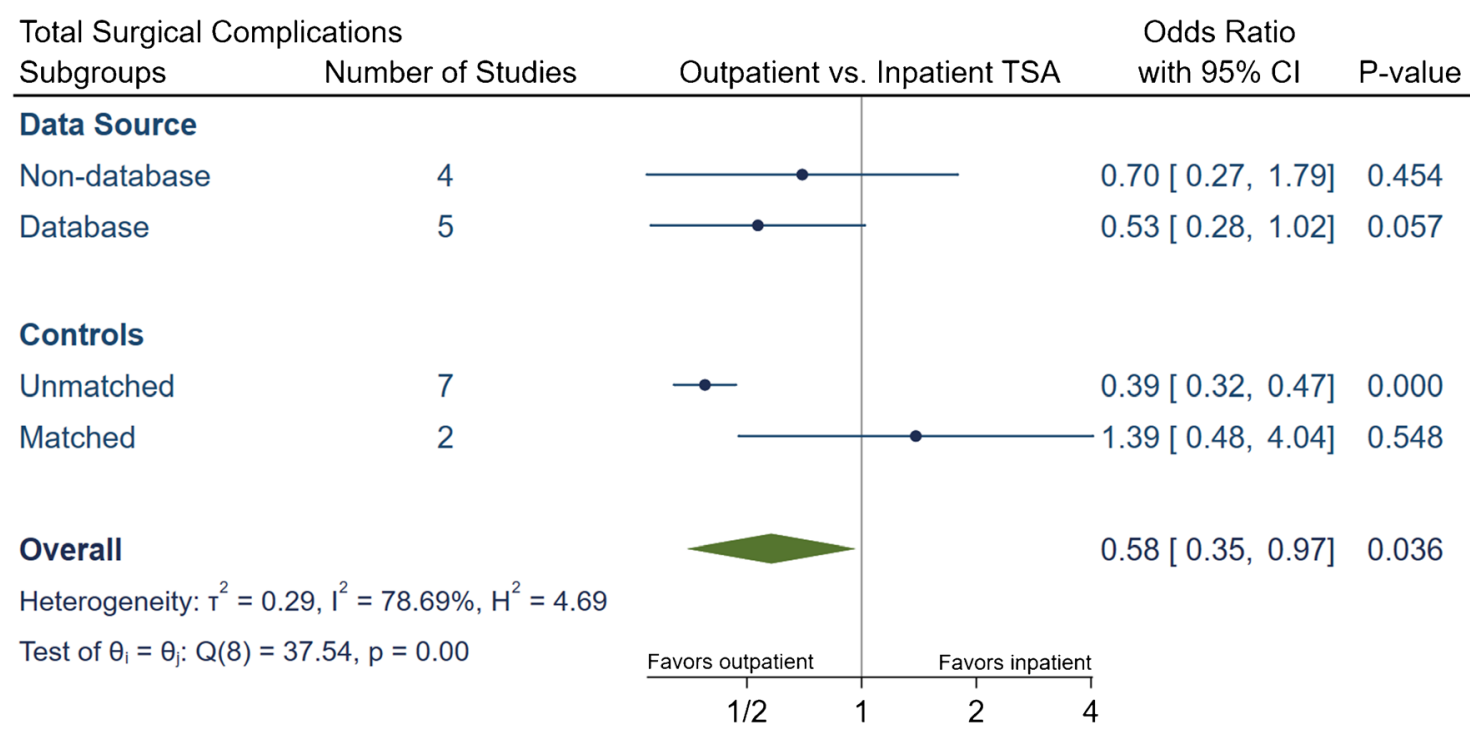

Random-effects DerSimonian-Laird model

Fig. 4 Comparison of overall total surgical complications between outpatient and inpatient total shoulder arthroplasty (TSA) with subgroup analyses for data source and controls. CI: confidence interval

\section{Costs}

Two comparative studies have investigated the financial costs of outpatient TSA. Cancienne et al. [8] reported that the 30day post-operative reimbursement for the outpatient group was $\$ 14,722$ per patient compared to inpatients which was $\$ 18,336$ per patient. In addition, they specifically found that outpatient TSA had a statistically significant reduction in PACU costs, laboratory costs, physical and occupational therapy costs, and narcotic prescriptions. However, outpatient TSA had increased costs for antiemetic and anticoagulation prescription costs.
In the most recent study by Ode et al. [25], the charges including surgery costs and the episode of care were compared across five states. They found that the outpatient setting has resulted in a $40 \%$ decrease in charges with the state where the surgery has been performed was the strongest predictor.

\section{Discussion}

The objective of this systematic review and meta-analysis was to evaluate the safety of outpatient TSA by comparing readmissions and complications with inpatient TSA. The

\begin{tabular}{|c|c|c|c|c|}
\hline \multicolumn{2}{|c|}{ Major Surgical Complications } & Outpatient vs. Inpatient TSA & $\begin{array}{l}\text { Odds Ratio } \\
\text { with } 95 \% \mathrm{Cl}\end{array}$ & P-value \\
\hline \multicolumn{5}{|l|}{ Data Source } \\
\hline Non-database & 4 & & $0.70[0.38,1.31]$ & 0.267 \\
\hline Database & 5 & & $0.64[0.39,1.08]$ & 0.093 \\
\hline \multicolumn{5}{|l|}{ Controls } \\
\hline Unmatched & 7 & $\longrightarrow$ & $0.52[0.40,0.68]$ & 0.000 \\
\hline Matched & 2 & & $-1.09[0.80,1.47]$ & 0.597 \\
\hline \multirow{3}{*}{\multicolumn{2}{|c|}{$\begin{array}{l}\text { Overall } \\
\text { Heterogeneity: } \mathrm{T}^{2}=0.11, \mathrm{I}^{2}=47.03 \%, \mathrm{H}^{2}=1.89 \\
\text { Test of } \theta=\theta \cdot \mathrm{Q}(8)=15.10, \mathrm{p}=0.06\end{array}$}} & 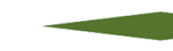 & $0.67[0.46,0.97]$ & 0.035 \\
\hline & & & & \\
\hline & & & & \\
\hline & & $1 / 2$ & & \\
\hline
\end{tabular}

Random-effects DerSimonian-Laird model

Fig. 5 Comparison of overall major surgical complications between outpatient and inpatient total shoulder arthroplasty (TSA) with subgroup analyses for data source and controls. CI: confidence interval 


\begin{tabular}{|c|c|c|c|c|c|}
\hline \multicolumn{4}{|c|}{ Minor Surgical Complications } & \multicolumn{2}{|l|}{ Odds Ratio } \\
\hline Subgroups & Number of Studies & \multicolumn{2}{|c|}{ Outpatient vs. Inpatient TSA } & with $95 \% \mathrm{Cl}$ & P-value \\
\hline \multicolumn{6}{|l|}{ Data Source } \\
\hline Non-database & 4 & & & $0.77[0.16,3.81]$ & 0.748 \\
\hline Database & 5 & & & $2.37[0.32,17.69]$ & 0.401 \\
\hline \multicolumn{6}{|l|}{ Controls } \\
\hline Unmatched & 7 & & & $0.72[0.24,2.16]$ & 0.559 \\
\hline Matched & 2 & & 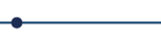 & $-3.84[0.52,28.31]$ & 0.187 \\
\hline \multicolumn{4}{|l|}{ Overall } & $1.10[0.37$ & 0.863 \\
\hline \multicolumn{6}{|c|}{ Heterogeneity: $\mathrm{T}^{2}=1.07, \mathrm{I}^{2}=51.46 \%, \mathrm{H}^{2}=2.06$} \\
\hline \multicolumn{6}{|c|}{ Test of $\theta_{\mathrm{i}}=\theta_{\mathrm{j}}: \mathrm{Q}(8)=16.48, \mathrm{p}=0.04$} \\
\hline & & $1 / 4$ & 16 & & \\
\hline
\end{tabular}

Random-effects DerSimonian-Laird model

Fig. 6 Comparison of overall minor surgical complications between outpatient and inpatient total shoulder arthroplasty (TSA) with subgroup analyses for data source and controls. CI: confidence interval

rationale behind this study was that TSA is a successful procedure, yet its incidence is rapidly increasing which results in significant expenditures on health care systems. To maximize value through achieving high-quality care with the least possible costs, outpatient TSA would be advantageous in entertaining this notion. The success of outpatient total hip and knee arthroplasty in reducing costs while retaining equivalent outcomes to the inpatient setting is well-established, which has motivated surgeons to implement outpatient TSA. Our systematic review and meta-analytic comparisons demonstrated that outpatient TSA is equivalent to inpatient settings in terms of readmissions and complications while achieving satisfactory functional outcomes and reducing costs.

A vital aspect of performing outpatient TSA is careful patient risk stratification [14]. This aspect is crucial in maintaining satisfactory outcomes without further increase in complications. In our systematic review, unmatched cohort studies had significantly younger age groups in outpatient TSA and in most; the population was predominant in males as opposed to inpatient TSA. The disproportionate number of younger patients in the outpatient group can be explained by the fact that younger patients have less comorbidities and are thus safer for the outpatient pathway. However, the under representation of females in the outpatient groups could be related to surgeon selection bias, as female sex has been reported to be a significant predictor for longer hospitalization [30, 31]. Another finding in this review was that the outpatient group was generally healthier than their inpatient counterparts. In unmatched studies, outpatient TSA had significantly fewer proportions of ASA class III, diabetes mellitus, combined cardiopulmonary comorbidities, isolated cardiovascular diseases, and hypertension. Unmatched studies are helpful as they reflect the trends of patient stratification in the current practice for outpatient arthroplasty, hence this emphasizes that appropriate patient selection is key in performing a successful outpatient TSA.

The safety and savings of outpatient arthroplasty can be assessed through investigating readmission rates which our meta-analytic comparisons did not show any differences at 30 and 90 days. Our findings were comparable to most included studies, thereby supporting that outpatient TSA is a safe option that does not translate into increased readmissions. The only contradicting evidence was reported by Basques et al. [28] who reported increased re-admission in inpatient groups at 90 days using Medicare data, which could relate to inherent limitations in the Medicare database such as coding errors. Of interest, Cancienne et al. [8] reported in their matched-cohort on a national insurance database that risk factors for readmissions within 90 days include obesity, diabetes mellitus, peripheral vascular disease, congestive heart failure, chronic lung disease, depression, and chronic anemia in both outpatient and inpatient groups. In another database study, Ode et al. [25] performed logistic regression analysis and found that readmissions were markedly increased in obese patients and were also strongly affected by the state that the procedure was performed.

Another finding of this study was that outpatient TSA was not associated with increased complications when compared with inpatient TSA. Unadjusted meta-analytic comparisons demonstrated that outpatient TSA was associated with reduced surgical (total and major) and medical complications (total, major and minor). It is important to acknowledge that this analysis included matched and nonmatched retrospective cohort studies. Therefore, subgroup analyses were constructed to further explore the outcomes of outpatient TSA. The subgroup analyses demonstrated if a study was matched, there was no significant difference in complications between 


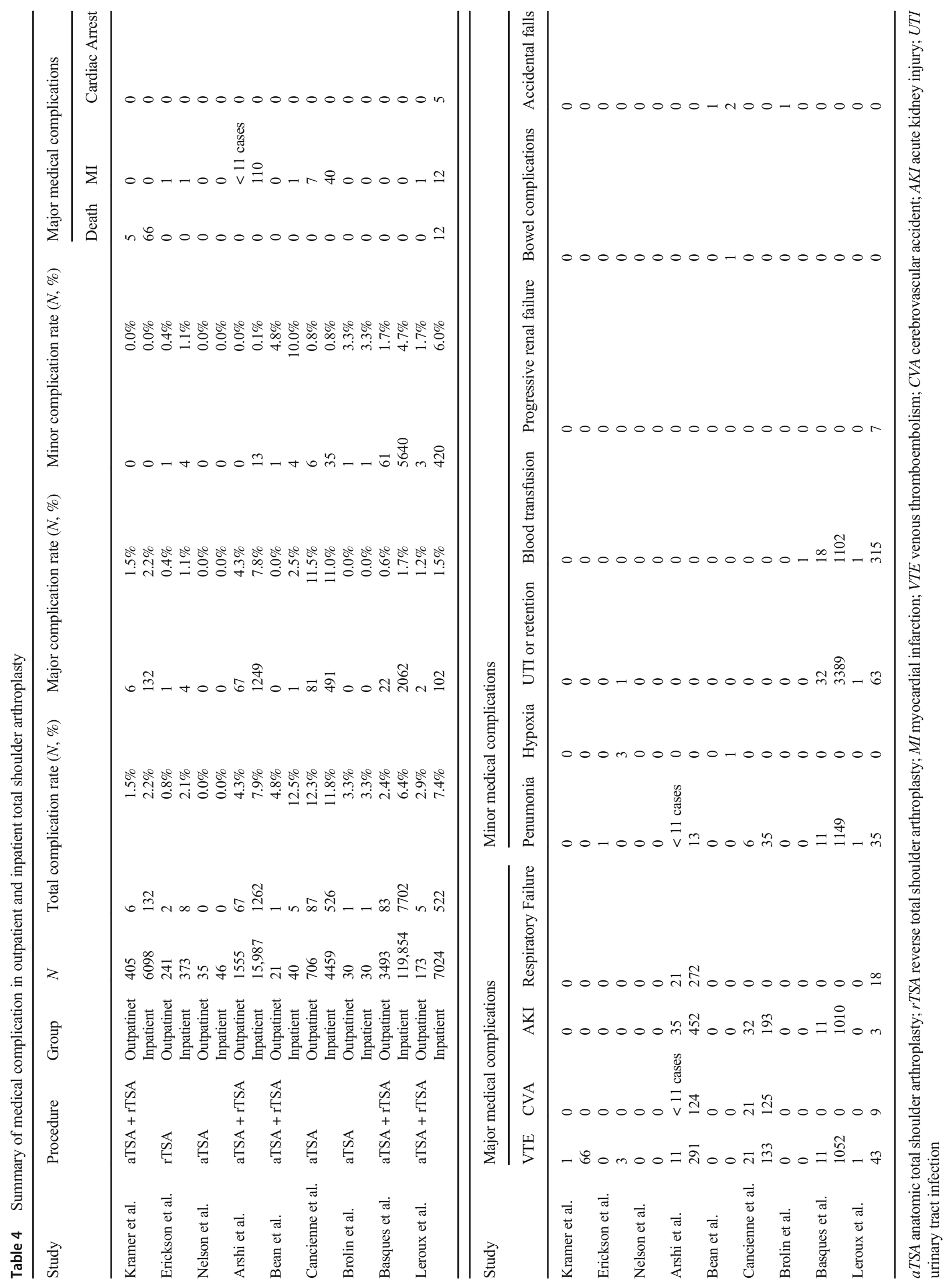




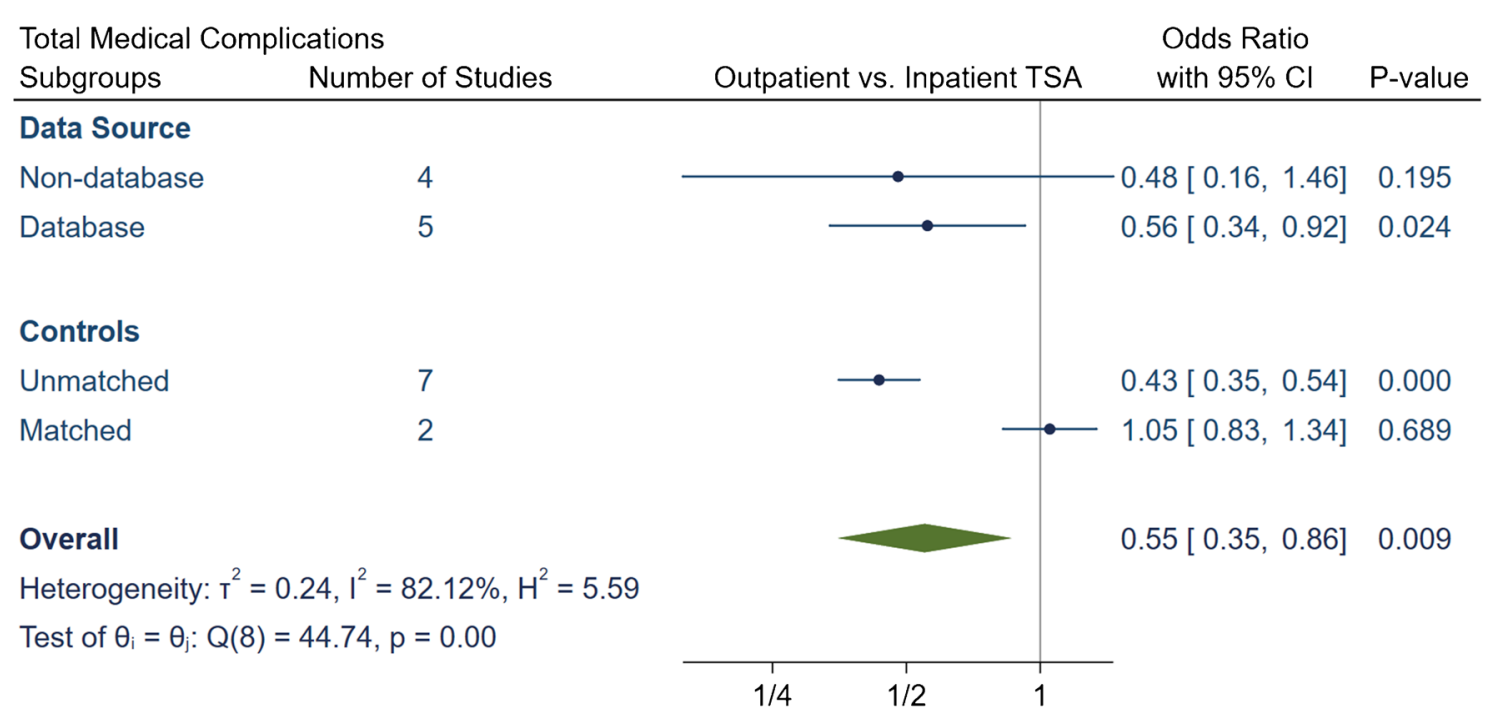

Random-effects DerSimonian-Laird model

Fig. 7 Comparison of overall total medical complications between outpatient and inpatient total shoulder arthroplasty (TSA) with sub-group analyses for data source and controls. CI: confidence interval

outpatient and inpatient TSA for all surgical and medical complications whether major or minor. In addition, no difference in all complications was evident regardless of a study's data source (i.e., database or nondatabase). Such findings suggest that outpatient TSA is noninferior to the inpatient pathway, and it can be performed safely with careful patient selection.

The cost reductions observed in outpatient arthroplasty have been well documented in the hip and knee literature $[11,13]$. Early studies of outpatient TSA have also shown this cost saving benefit. In our systematic review, only two comparative studies reported costs with significant reduction following outpatient arthroplasty. The cost advantage of outpatient TSA is supported as well in a recent economic analysis, where inpatient TSA costs were estimated $\$ 76,000$ compared to $\$ 23,000$ for outpatient TSA [32]. Although the costs of inpatient arthroplasty are attributed to the increased complexity of the surgical cases and the presence of comorbidities, increased expenditures in the care pathway might include unnecessary costs that could be circumvented. Therefore, the authors performed a secondary analysis that excluded ancillary costs such as additional laboratory workup, imaging studies, and inpatient rehabilitation. Even following these exclusions, the costs of inpatient TSA were still $41 \%$ higher than outpatient TSA [32].

Several limitations to this systematic review should be acknowledged. For example, our qualitative review

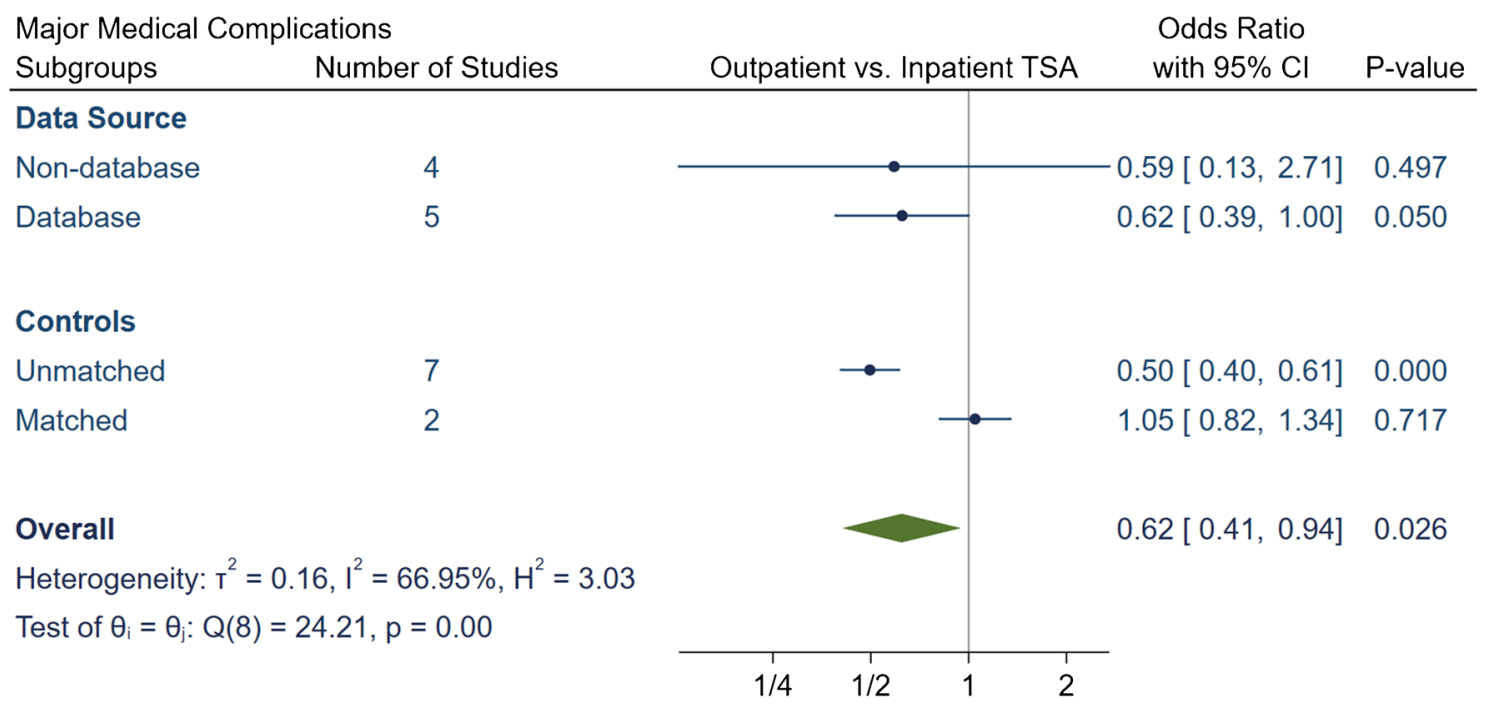

Random-effects DerSimonian-Laird model

Fig. 8 Comparison of overall major medical complications between outpatient and inpatient total shoulder arthroplasty (TSA) with subgroup analyses for data source and controls. CI: confidence interval 


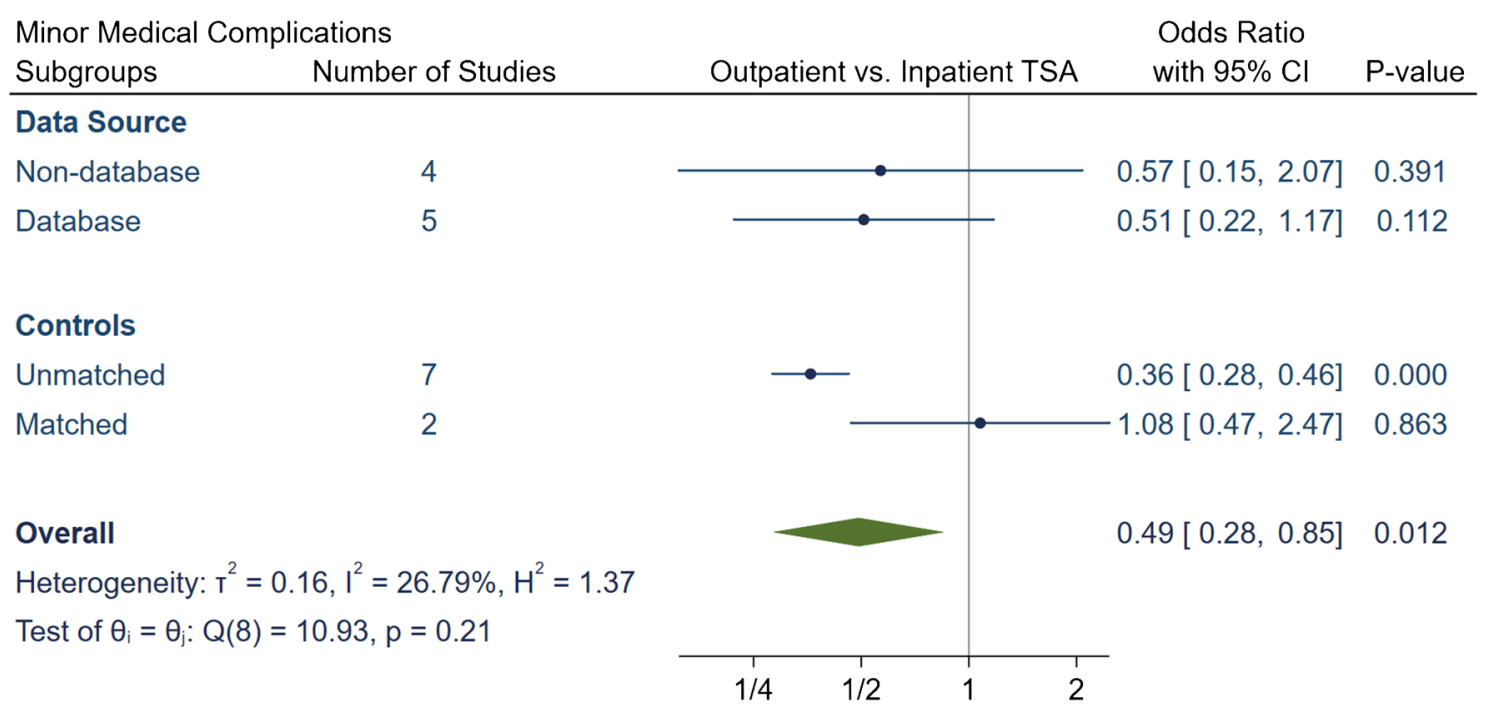

Random-effects DerSimonian-Laird model

Fig. 9 Comparison of overall minor medical complications between outpatient and inpatient total shoulder arthroplasty (TSA) with subgroup analyses for data source and controls. CI: confidence interval

demonstrated that most included studies were poor in quality, with significant confounding bias in six out of ten studies and selection bias in seven out of ten studies. The level of evidence of the review is level III with all studies being retrospective cohorts, indicating a lack of high-level evidence. Another limitation was heterogeneity among the studies as we included different data sources (database and nondatabase) and different matching of controls. Outcomes measures that had low heterogeneity were the 30-day readmissions, minor medical complications, and revision rates. Moderate heterogeneity was encountered in the 90-day readmissions, major and minor surgical complications. Substantial heterogeneity was found in total surgical and medical complications, and major medical complications. Substantial heterogeneity in total complications was addressed by subgrouping total complications into major and medical complications. The remaining heterogeneity in other outcomes was addressed by further subgrouping outcomes based on data source and controls matching.
Furthermore, database studies have several inherent limitations such as the accuracy of the data is affected by coding errors. In our study, total surgical and medical complications were limited by having. Additionally, database study may not capture important variables that could potentially confound the rate of readmissions and complications such as surgeon or hospital volume and surgical technique. Despite that we employed subgroup analyses to control for study-level variables such as matched control or data source, we could not account for the type of procedure such as anatomic or reverse TSA due to limitations in data extraction. An important final limitation was that we did not register this systematic review prospectively which would have improved the transparency of this study.

In conclusion, our systematic review and meta-analysis demonstrated that outpatient TSA could be a safe and effective alternative to inpatient TSA in appropriately selected patients. It was evident that outpatient TSA does not lead to

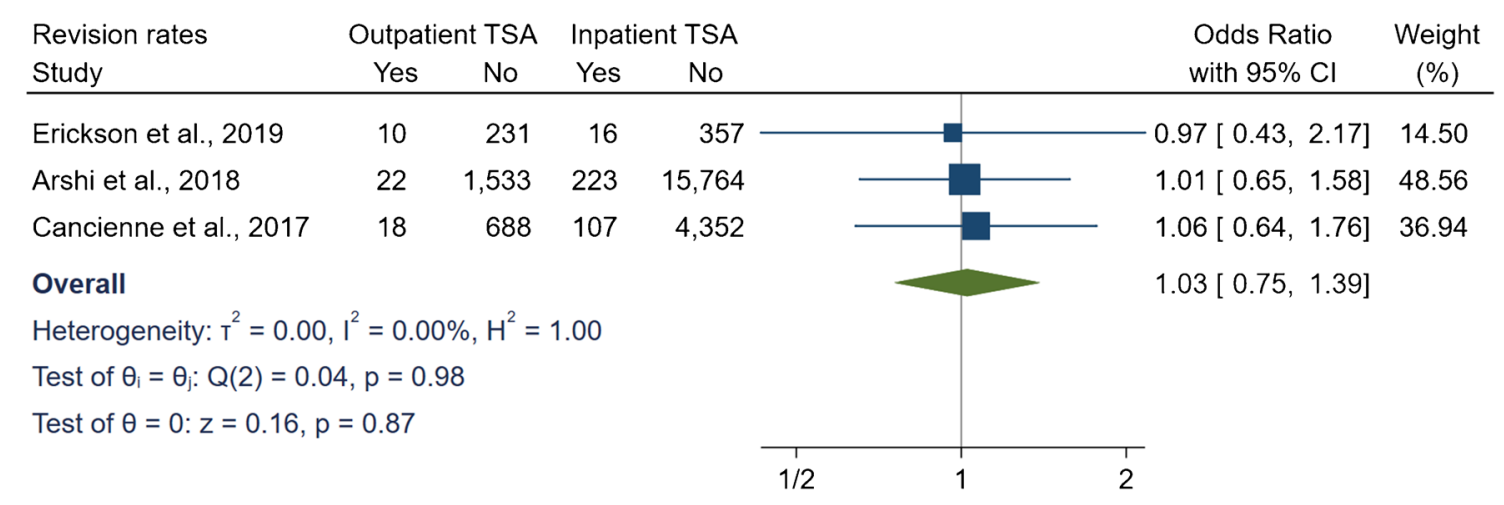

Random-effects DerSimonian-Laird model

Fig. 10 Comparison of revision rates between outpatient and inpatient total shoulder arthroplasty (TSA) with subgroup analyses for data source and controls. CI: confidence interval 
increased re-admissions or complication rates. An additional benefit of outpatient TSA was the significant cost reductions in comparative studies. This meta-analysis is based on retrospective comparative studies with level three evidence. Prospective and randomized, controlled multicenter studies are still necessary to ascertain the differences in outcomes between both inpatient and outpatient TSA.

Supplementary Information The online version contains supplementary material available at https://doi.org/10.1007/s00264-021-04940-7.

Authors' contributions AH and AT researched the literature. AFA performed the statistical analysis and wrote both the method and result sections. $\mathrm{OZ}$ wrote the introduction section. SM and SQ assisted in editing the whole manuscript. SQ, GOA, and MAA provided overall supervision of conducting this review.

Funding Open access funding provided by the Qatar National Library.

Data availability Not applicable.

\section{Compliance with ethical standards}

Conflict of interest The authors declare that they have no conflict of interest.

Consent to participate Not applicable.

Consent for publication Not applicable.

Code availability Not applicable

Open Access This article is licensed under a Creative Commons Attribution 4.0 International License, which permits use, sharing, adaptation, distribution and reproduction in any medium or format, as long as you give appropriate credit to the original author(s) and the source, provide a link to the Creative Commons licence, and indicate if changes were made. The images or other third party material in this article are included in the article's Creative Commons licence, unless indicated otherwise in a credit line to the material. If material is not included in the article's Creative Commons licence and your intended use is not permitted by statutory regulation or exceeds the permitted use, you will need to obtain permission directly from the copyright holder. To view a copy of this licence, visit http://creativecommons.org/licenses/by/4.0/.

\section{References}

1. Trofa D, Rajaee SS, Smith EL (2014) Nationwide trends in total shoulder arthroplasty and hemiarthroplasty for osteoarthritis. Am J Orthop (Belle Mead NJ) 43:166-172

2. Kim SH, Wise BL, Zhang Y, Szabo RM (2011) Increasing incidence of shoulder arthroplasty in the United States. J Bone Joint Surg Am 93:2249-2254. https://doi.org/10.2106/JBJS.J.01994

3. Day JS, Lau E, Ong KL, Williams GR, Ramsey ML, Kurtz SM (2010) Prevalence and projections of total shoulder and elbow arthroplasty in the United States to 2015. J Shoulder Elb Surg 19: 1115-1120. https://doi.org/10.1016/j.jse.2010.02.009
4. Schairer WW, Nwachukwu BU, Lyman S, Craig EV, Gulotta LV (2015) National utilization of reverse total shoulder arthroplasty in the United States. J Shoulder Elb Surg 24:91-97. https://doi.org/10. 1016/j.jse.2014.08.026

5. Chin PY, Sperling JW, Cofield RH, Schleck C (2006) Complications of total shoulder arthroplasty: are they fewer or different? J Shoulder Elb Surg 15:19-22. https://doi.org/10.1016/ j.jse.2005.05.005

6. Singh JA, Ramachandran R (2015) Age-related differences in the use of total shoulder arthroplasty over time: use and outcomes. Bone Joint J 97-B:1385-1389. https://doi.org/10.1302/0301620X.97B10.35696

7. Chalmers PN, Kahn T, Broschinsky K, Ross H, Stertz I, Nelson R, Yoo M, Tashjian RZ (2019) An analysis of costs associated with shoulder arthroplasty. J Shoulder Elb Surg 28:1334-1340. https:// doi.org/10.1016/j.jse.2018.11.065

8. Cancienne JM, Brockmeier SF, Gulotta LV, Dines DM, Werner BC (2017) Ambulatory total shoulder arthroplasty: a comprehensive analysis of current trends, complications, readmissions, and costs. J Bone Joint Surg Am 99:629-637. https://doi.org/10.2106/ JBJS.16.00287

9. Berger RA, Sanders SA, Thill ES, Sporer SM, Della Valle C (2009) Newer anesthesia and rehabilitation protocols enable outpatient hip replacement in selected patients. Clin Orthop Relat Res 467:1424 1430. https://doi.org/10.1007/s11999-009-0741-x

10. Dorr LD, Thomas DJ, Zhu J, Dastane M, Chao L, Long WT (2010) Outpatient total hip arthroplasty. J Arthroplast 25:501-506. https:// doi.org/10.1016/j.arth.2009.06.005

11. Bertin KC (2005) Minimally invasive outpatient total hip arthroplasty: a financial analysis. Clin Orthop Relat Res:154-163. https://doi.org/10.1097/01.blo.0000157173.22995.cf

12. Berger RA, Sanders S, D'Ambrogio E, Buchheit K, Deirmengian C, Paprosky W, Della Valle CJ, Rosenberg AG (2006) Minimally invasive quadriceps-sparing TKA: results of a comprehensive pathway for outpatient TKA. J Knee Surg 19:145-148. https://doi.org/ $10.1055 / \mathrm{s}-0030-1248097$

13. Lovald ST, Ong KL, Malkani AL, Lau EC, Schmier JK, Kurtz SM, Manley MT (2014) Complications, mortality, and costs for outpatient and short-stay total knee arthroplasty patients in comparison to standard-stay patients. J Arthroplast 29:510-515. https://doi.org/10. 1016/j.arth.2013.07.020

14. Fournier MN, Brolin TJ, Azar FM, Stephens R, Throckmorton TW (2019) Identifying appropriate candidates for ambulatory outpatient shoulder arthroplasty: validation of a patient selection algorithm. J Shoulder Elb Surg 28:65-70. https://doi.org/10.1016/j.jse.2018.06. 017

15. Zomar BO, Sibbald SL, Bickford D, Howard JL, Bryant DM, Marsh JD, Lanting BA (2020) Implementation of outpatient total joint arthroplasty in Canada: where we are and where we need to go. Orthop Res Rev 12:1-8. https://doi.org/10.2147/ORR.S239386

16. Bean BA, Connor PM, Schiffern SC, Hamid N (2018) Outpatient shoulder arthroplasty at an ambulatory surgery center using a multimodal pain management approach. J Am Acad Orthop Surg Glob Res Rev 2:e064. https://doi.org/10.5435/JAAOSGlobal-D-1800064

17. Brolin TJ, Mulligan RP, Azar FM, Throckmorton TW (2017) Neer Award 2016: outpatient total shoulder arthroplasty in an ambulatory surgery center is a safe alternative to inpatient total shoulder arthroplasty in a hospital: a matched cohort study. J Shoulder Elb Surg 26:204-208. https://doi.org/10.1016/j.jse.2016.07.011

18. Erickson BJ, Shishani Y, Jones S, Sinclair T, Griffin J, Romeo AA, Gobezie R (2020) Outpatient vs. inpatient reverse total shoulder arthroplasty: outcomes and complications. J shoulder elbow Surg. https://doi.org/10.1016/j.jse.2019.10.023

19. Nelson CG, Murphy WG, Mulligan RP, Brolin TJ, Azar FM, Throckmorton TW (2019) A retrospective comparative study of 
patient satisfaction following ambulatory outpatient and inpatient total shoulder arthroplasty. Current Orthopaedic Practice 30:435438. https://doi.org/10.1097/bco.0000000000000787

20. Gallay SH, Lobo JJ, Baker J, Smith K, Patel K (2008) Development of a regional model of care for ambulatory total shoulder arthroplasty: a pilot study. Clin Orthop Relat Res 466:563-572. https://doi.org/10.1007/s1 1999-007-0083-5

21. Moher D, Liberati A, Tetzlaff J, Altman DG, Group P (2010) Preferred reporting items for systematic reviews and meta-analyses: the PRISMA statement. Int J Surg 8:336-341. https://doi.org/10. 1016/j.ijsu.2010.02.007

22. Gupta AK, Chalmers PN, Rahman Z, Bruce B, Harris JD, McCormick F, Abrams GD, Nicholson GP (2014) Reverse total shoulder arthroplasty in patients of varying body mass index. J Shoulder Elb Surg 23:35-42. https://doi.org/10.1016/j.jse.2013. 07.043

23. Dindo D, Demartines N, Clavien PA (2004) Classification of surgical complications: a new proposal with evaluation in a cohort of 6336 patients and results of a survey. Ann Surg 240:205-213. https://doi.org/10.1097/01.sla.0000133083.54934.ae

24. Sterne JA, Hernan MA, Reeves BC, Savovic J, Berkman ND, Viswanathan M, Henry D, Altman DG, Ansari MT, Boutron I, Carpenter JR, Chan AW, Churchill R, Deeks JJ, Hrobjartsson A, Kirkham J, Juni P, Loke YK, Pigott TD, Ramsay CR, Regidor D, Rothstein HR, Sandhu L, Santaguida PL, Schunemann HJ, Shea B, Shrier I, Tugwell P, Turner L, Valentine JC, Waddington H, Waters E, Wells GA, Whiting PF, Higgins JP (2016) ROBINS-I: a tool for assessing risk of bias in non-randomised studies of interventions. BMJ 355:i4919. https://doi.org/10.1136/bmj.i4919

25. Ode GE, Odum S, Connor PM, Hamid N (2020) Ambulatory versus inpatient shoulder arthroplasty: a population-based analysis of trends, outcomes, and charges. JSES Int 4:127-132. https://doi.org/ 10.1016/j.jses.2019.10.001

26. Leroux TS, Basques BA, Frank RM, Griffin JW, Nicholson GP, Cole BJ, Romeo AA, Verma NN (2016) Outpatient total shoulder arthroplasty: a population-based study comparing adverse event and readmission rates to inpatient total shoulder arthroplasty. J Shoulder Elb Surg 25:1780-1786. https://doi.org/10.1016/j.jse. 2016.04.006

27. Kramer JD, Chan PH, Prentice HA, Hatch J, Dillon MT, Navarro RA (2019) Same-day discharge is not inferior to longer length of inhospital stay for 90-day readmissions following shoulder arthroplasty. J Shoulder Elb Surg. https://doi.org/10.1016/j.jse. 2019.09.037

28. Basques BA, Erickson BJ, Leroux T, Griffin JW, Frank RM, Verma NN, Romeo AA (2017) Comparative outcomes of outpatient and inpatient total shoulder arthroplasty: an analysis of the Medicare dataset. Bone Joint J 99-B:934-938. https://doi.org/10. 1302/0301-620X.99B7.BJJ-2016-0976.R1

29. Arshi A, Leong NL, Wang C, Buser Z, Wang JC, Vezeridis PS, McAllister DR, Petrigliano FA (2018) Relative complications and trends of outpatient total shoulder arthroplasty. Orthopedics 41: e400-e409. https://doi.org/10.3928/01477447-20180409-01

30. Matsen FA 3rd, Li N, Gao H, Yuan S, Russ SM, Sampson PD (2015) Factors affecting length of stay, readmission, and revision after shoulder arthroplasty: a population-based study. J Bone Joint Surg Am 97:1255-1263. https://doi.org/10.2106/JBJS.N.01107

31. Menendez ME, Lawler SM, Carducci MP, Ring D, Mahendraraj KA, Jawa A (2019) Delayed hospital discharge after total shoulder arthroplasty: why, and who is at risk? JSES Open Access 3:130 135. https://doi.org/10.1016/j.jses.2019.07.011

32. Gregory JM, Wetzig AM, Wayne CD, Bailey L, Warth RJ (2019) Quantification of patient-level costs in outpatient total shoulder arthroplasty. J Shoulder Elb Surg 28:1066-1073. https://doi.org/ 10.1016/j.jse.2018.10.006

Publisher's note Springer Nature remains neutral with regard to jurisdictional claims in published maps and institutional affiliations. 